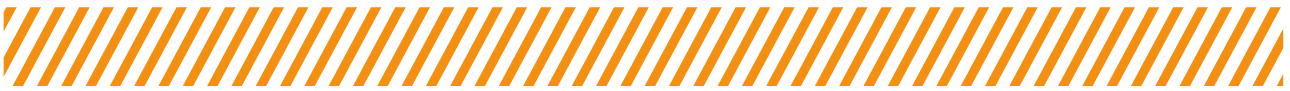

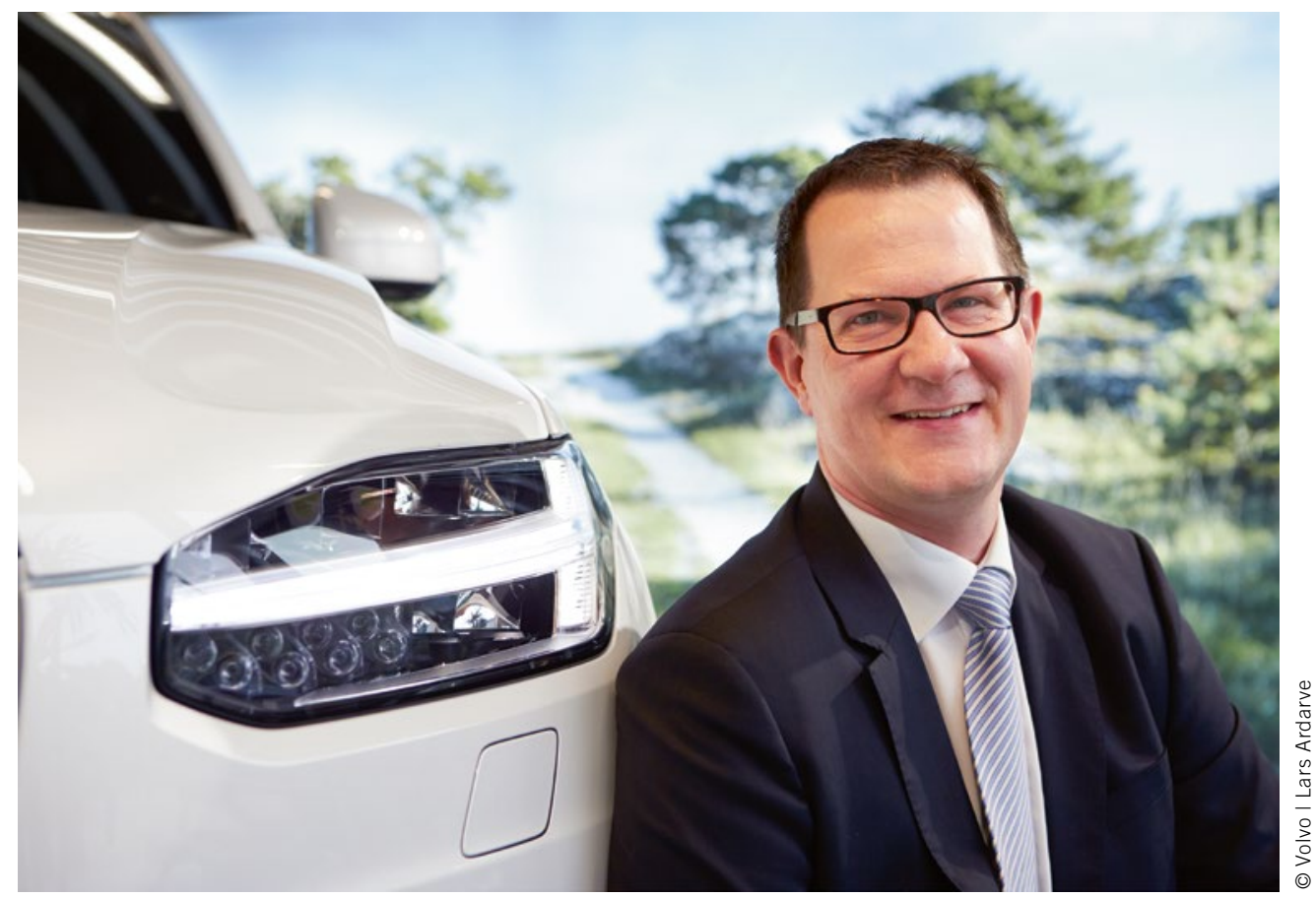

Dr. Thomas M. Müller

Bereichsleiter Elektrik/Elektronik \& Chassis Volvo Car Group in Göteborg (Schweden)

\section{Runder Tisch}

\section{für eine gemeinsame Telematik-Datenbank}

Heute gibt es kaum einen Automobilhersteller, der keine vernetzten Funktionen im Angebot hat oder zumindest mit Hochdruck daran arbeitet. Die Branche bietet immer mehr Funktionen an. Diese sind teils tiefer integriert wie Telematikdienste oder teils weniger tief integriert wie im Fall von Apps beispielsweise über CE-Geräte-Schnittstellen. Dabei spielen sowohl Time to Market als auch Kosten eine Rolle bei der Entscheidung.

Doch was zählt zukünftig im Bereich des vernetzten Fahrzeugs? Wenden wir unseren Blick auf eine andere Diskussion, so wird aus meiner Sicht klar, worauf wir uns als Industrie und ich meine hier nicht nur einzelne OEMs im durchaus positiven und erwünschten Wettbewerb miteinander - fokussieren müssen: die Unterstützung der Fahrerassistenz und der Automatisierung des Fahrens in allen noch vor uns liegenden Ausbaustufen. Denn die entsprechenden Techniken werden meiner Meinung nach ein Schlüssel zur Reduzierung von Verkehrsunfällen und -toten sein. Ebenso leisten sie einen Beitrag zur Entlastung des Verkehrs in Spitzenzeiten.

Hierzu sind Voraussetzungen zu schaffen: Die Fahrzeuge müssen im Crowd Sourcing permanent Daten mit einem Backend austauschen. Nur so gelingt es, dass aus Informationen wie Ort, Geschwindigkeit und weiteren Informationen wie Störungen oder fahrbahnbezogene Parameter ein möglichst gutes Abbild des Fahrzeugumfelds im Backend erzeugt werden kann - inklusive des dynamischen Anteils des elektronischen Horizonts. Jedes Fahrzeug soll auf die relevanten Szenarien reagieren können.

Ein mögliches und greifbares Szenario besteht dabei in der Nutzung von im Fahrzeug verbauten Telematikeinheiten mit SIM-Karte. Diese sammeln die anonymisierten Daten zum Wohle aller in einer zentralen Datenbank, die dann von allen Autoherstellern zur Modellierung der unmittelbaren und ferneren Fahrzeugumgebung sowie der Entwicklung neuer Funktionen genutzt werden können. Kein OEM - so groß er auch sein mag - kann diese Aufgabe allein bewältigen, will er sich nicht beschränken auf Meldungen von Fahrzeugen der eigenen Marke, was aus Kundensicht in meinen Augen nicht akzeptabel ist. Hier ist die Automobilindiustrie als Ganzes gefordert.

Die gesetzliche Einführung des eCalls bildet dabei für Europa in meinen Augen eine hervorragende Möglichkeit, da die Kosten im Fahrzeug für ein obiges Szenario bereits (fast) alle gedeckt sind. Aus meiner Sicht sollten sich die Automobilhersteller gemeinsam dringend an einen runden Tisch setzen und die hierfür notwendigen Standards sowie Hosting und Betrieb einer Backend-Infrastruktur diskutieren. Wir dürfen nicht warten, denn es geht ja schließlich um die Rettung von Menschenleben. 